Artigo Original

Original Article

\author{
Joviane Bagolin Bonini1,2 \\ Márcia Keske-Soares ${ }^{1,3,2}$
}

Descritores

Fala

Fonoterapia

Linguística

Transtorno Fonológico

Criança

Keywords

Speech

Speech Therapy

Linguistics

Speech Sound Disorder

Child

Endereço para correspondência:

Joviane Bagolin Bonini

Programa de Pós-graduação em

Distúrbios da Comunicação Humana,

Universidade Federal de Santa Maria

- UFSM

Av. Rio Branco, 601, sala 3,

$4^{\circ}$ andar, Santa Maria (RS), Brasil,

CEP: 97010-423.

E-mail: jovianesm@gmail.com

Recebido em: Agosto 21, 2017

\section{Pseudopalavras para terapia fonológica validadas por juizes especialistas}

\author{
Pseudowords to phonological therapy \\ validated by expert judges
}

\section{RESUMO}

Objetivo: Criar uma lista de pseudopalavras baseada em ambientes favorecedores e submeter esta ao julgamento de juízes especialistas, a fim de se obter uma lista validada de pseudopalavras que possam ser utilizadas em terapia. Método: Buscou-se um estudo que analisou os ambientes favorecedores de todos os fonemas do Português Brasileiro e, a partir de seus dados, criou-se uma lista de pseudopalavras para cada fonema, em diferentes níveis de favorecimento. A amostra julgadora da lista foi composta por dez juízes que analisaram as pseudopalavras. Esta análise foi realizada em duas etapas distintas. Na primeira etapa, cinco juízes analisaram quais as melhores pseudopalavras. Na segunda etapa, os outros cinco juízes julgaram se as pseudopalavras eram essenciais para a terapia. A análise de concordância entre os juízes foi realizada por meio da Razão de Validade de Conteúdo. Resultados: Os juízes da primeira etapa analisaram e reduziram consideravelmente o número de pseudopalavras, que passou de 4000 no total para 1547. E, com a análise estatística utilizada sobre os dados obtidos com os juízes da segunda etapa, a lista de pseudopalavras com validade de conteúdo foi reduzida a poucas opções. Os juízes apontaram a simplicidade na estrutura das pseudopalavras como um critério de seleção. Conclusão: $\mathrm{O}$ julgamento dos juízes especialistas resultou em um pequeno número de pseudopalavras que apresentam validade de conteúdo e podem ser utilizadas na terapia fonológica.werty

\begin{abstract}
Purpose: Create a pseudowords list based on favorable environments and submit this to the judgment of expert judges, to obtain a validated list of pseudowords that can be used in therapy. Methods: A study that analyzed the favorable environments of all phonemes of Brazilian Portuguese was sought and, from their data, a pseudoword list for each phoneme, at different levels of favoring, was created. The judging sample of the list was composed of ten judges who reviewed thepseudowords. This analysis was performed in two distinct stages. In the first stage, five judges analyzed the bestpseudowords. In the second stage, the other five judges judged whether pseudowords were essential for therapy. The concordance analysis among the judges was performed through the Content Validity Ratio. Results: The judges of the first stage reviewed and considerably reduced the number ofpseudowords, from 4000 in total to 1547. And, with the statistical analysis used on the data obtained with the judges of the second stage, the pseudoword list with content validity was reduced to few options. The judges pointed to the simplicity in the structure of pseudowords as a selection criterion. Conclusion: The expert judges' judgment resulted in a small number of pseudowords that have content validity and can be used in phonological therapy.
\end{abstract}

Trabalho realizado na Universidade Federal de Santa Maria - UFSM, Centro de Estudos de Linguagem e Fala - CELF, referente a parte da tese de doutorado da primeira autora - Santa Maria (RS), Brasil.

${ }^{1}$ Programa de Pós-graduação em Distúrbios da Comunicação Humana, Universidade Federal de Santa Maria - UFSM - Santa Maria (RS), Brasil.

${ }^{2}$ Curso de Fonoaudiologia, Universidade Federal de Santa Maria - UFSM - Santa Maria (RS), Brasil.

${ }^{3}$ Programa de Pós-graduação em Linguística Aplicada, Pontifícia Universidade Católica do Rio Grande do Sul - PUCRS - Porto Alegre (RS), Brasil.

Fonte de financiamento: nada a declarar.

Conflito de interesses: nada a declarar. 


\section{INTRODUÇÃO}

Nas últimas décadas, houve um crescimento, por parte dos pais, na busca do diagnóstico e terapia do Desvio Fonológico (DF). Concomitantemente, surgiram diversos estudos no meio científico em relação à terapia fonológica ${ }^{(1-10)}$. Esses estudos com terapia fonológica trouxeram muitas contribuições e auxiliaram no aprimoramento desta, aproximando a teoria da prática clínica.

A terapia fonológica tem como objetivo principal adequar a fala da criança de acordo com o padrão adulto de sua língua e é indicada para crianças que apresentam um desenvolvimento fonológico atípico. A organização e práticas da terapia fonológica são baseadas em modelos terapêuticos que regem a estrutura das sessões de acordo com fundamentos teóricos. Existem diversos recursos que podem ser utilizados para potencializar a terapia fonológica, por exemplo, o tipo de palavra-alvo e os ambientes linguísticos que a envolvem ${ }^{(3,5,6,9)}$.

O modelo terapêutico de "Oposições Máximas"(11,12), amplamente utilizado na Fonoaudiologia, indica que a terapia deve ser realizada utilizando pares de palavras envolvendo Palavras Reais e Pseudopalavras. Entretanto, apesar de este modelo ser muito utilizado na clínica no Brasil, nota-se que, frequentemente, são utilizadas apenas palavras-alvo com significado, ou seja, Palavras Reais.

Em relação às palavras-alvo, na prática clínica, o terapeuta ocasionalmente encontra a seguinte dificuldade: selecionar palavras-alvo com significado que possuam apenas o fonema-alvo alterado na posição adequada. Diante disso, em alguns casos, o terapeuta acaba optando por outro fonema-alvo que possua mais opções de palavras-alvo, mesmo que com isso diminuam as possibilidades de generalizações.

Considerando que as palavras-alvo são um fator essencial e determinante na terapia, o presente estudo atentou para dois aspectos importantes na formação destas palavras-alvo: o tipo, sem significado, e os ambientes linguísticos. Como as pseudopalavras são o foco principal da pesquisa, optou-se pela incorporação da variável ambientes favorecedores na formação dos alvos.

As pseudopalavras, como o próprio nome indica, são palavras não reais, ou seja, palavras sem significado. Santos e Bueno ${ }^{(13)}$ as definem como estímulos que respeitam as regras da língua nativa, mas que não possuem nenhum significado conceitual. O processo de percepção e produção de pseudopalavras é bastante complexo para as crianças, por isso é muito utilizado em teste de avaliação de leitura, escrita e memória ${ }^{(13)}$ e deve, também, ser considerado como um recurso terapêutico que pode ser utilizado na prática clínica.

Outro recurso ao qual o terapeuta pode atentar na seleção das palavras-alvo são os ambientes favorecedores. Estes referem-se a um grupo de variáveis como posição do fonema-alvo na palavra, tonicidade, número de sílabas, contexto precedente e seguinte. Diversos estudos foram realizados e comprovaram a importância dos ambientes favorecedores no processo de aquisição fonológica e na seleção das palavras-alvo ${ }^{(3,5,9,14-18)}$.

Desta forma, partindo-se do princípio de que o fonoaudiólogo deve utilizar recursos que otimizem a terapia e, consequentemente, auxiliem no processo de aquisição da criança, considera-se que a seleção das palavras-alvo deve ser alvo de atenção. Por isso, o presente estudo criou uma lista de pseudopalavras para a terapia fonológica e a submeteu ao julgamento de juízes especialistas, a fim de obter um recurso confiável para a prática clínica. Ainda, optou-se por utilizar as pseudopalavras na terapia por serem um recurso pouco explorado no Brasil, e por seu uso ser mais frequente em instrumentos de avaliação e diagnóstico. Ressaltando que a elaboração de pseudopalavras envolvendo ambientes favorecedores no Português Brasileiro (PB) é recurso inovador.

A análise por juízes permite maior confiabilidade aos resultados do estudo. Esta análise é uma etapa dos procedimentos metodológicos realizados no estudo. Diversos estudos na Fonoaudiologia utilizaram a análise e concordância entre juízes como forma de análise metodológica ${ }^{(19-23)}$.

Logo, o presente trabalho teve por objetivo instituir uma lista de pseudopalavras baseada em ambientes favorecedores e submeter esta ao julgamento de juízes especialistas, a fim de se obter uma lista de pseudopalavras confiáveis para utilizar em terapia fonológica.

\section{MÉTODO}

Esta pesquisa caracteriza-se como exploratória, prospectiva e transversal, de caráter quantitativo. Está vinculada ao projeto "Novas Perspectivas Terapêuticas nos casos de Desvio Fonológico", aprovado no Comitê de Ética e Pesquisa institucional sob número 280539914.1.0000.5346.

As pseudopalavras, objeto de estudo desta pesquisa, foram elaboradas considerando os ambientes linguísticos de cada fonema. Para isso, utilizou-se como base os dados referentes aos ambientes favorecedores dos fonemas do PB apresentados em um estudo que abordou e analisou os ambientes favorecedores de todos os fonemas do PB considerando as variáveis, posição na palavra, número de sílabas, tonicidade, contexto precedente e seguinte ${ }^{(24)}$. A autora ainda realizou uma análise na qual obteve os pesos de favorecimento de cada variante, o que possibilita calcular o valor de qualquer palavra ou, no caso, de qualquer pseudopalavra criada. Assim, com base nos valores deste estudo ${ }^{(24)}$, foram criados no presente estudo uma lista de pseudopalavras para cada fonema do PB em cada nível de favorecimento (pouco favorecedor, neutro e favorecedor), buscando sempre uma harmonia na utilização das variáveis, a fim de abranger todas as variantes, pois estas representam as possibilidades de ocorrência no PB.

Em um primeiro momento, a lista foi constituída por, no mínimo, vinte pseudopalavras para cada fonema, em cada nível de favorecimento, totalizando 60 pseudopalavras por fonema, com um total de 1485 pseudopalavras. Entretanto, verificou-se que o material poderia ser ampliado, fornecendo mais dados para a análise, por isso, optou-se por calcular os pesos de cada fonema da pseudopalavra, além do fonema para qual ela havia sido criada. Exemplificando, criou-se a pseudopalavra [sa.'bi.ri], inicialmente para o fonema /r/, e, na ampliação da lista, calculou-se o valor de favorecimento do alvo para os fonemas /b/e /s/ também, e incorporou-se a pseudopalavra na lista dos fonemas $/ \mathrm{b} / \mathrm{e} / \mathrm{s} /$, de acordo com seus níveis de favorecimento. Com isso, a lista ficou com um número muito elevado de pseudopalavras para cada fonema, principalmente na classe das plosivas. Isto porque um dos critérios utilizados na criação das pseudopalavras foi procurar sempre que possível utilizar fonemas menos complexos que o fonema-alvo em questão, para 
minimizar possíveis dificuldades. Por isso, fez-se necessária uma seleção destas pseudopalavras por juízes especialistas.

Para tal, um Grupo de Juízes Especialistas 1 (GJ1), composto por 5 doutores com prática em áreas relacionadas à Fala (terapia fonológica, linguística, fonologia), foi instruído a verificar quais eram as melhores pseudopalavras para serem utilizadas na terapia fonológica. Ressalta-se que todos os juízes assinaram o Termo de Consentimento Livre e Esclarecido (TCLE), no qual autorizaram sua participação na pesquisa como julgadores.

Os juízes foram orientados a selecionar e julgar quais as 10 melhores pseudopalavras de cada fonema em cada nível de favorecimento. Destaca-se que os juízes não foram informados quais eram os níveis de favorecimento, para não haver preferência pelos alvos favorecedores, ou seja, os juízes receberam três listas de pseudopalavras para cada fonema e foram solicitados a julgar quais as 10 melhores pseudopalavras de cada lista.

Os dados obtidos pela avaliação do GJ1 foram tabulados e submetidos à análise através da porcentagem de concordância absoluta. Em função da grande variabilidade de resposta, lembrando que a lista de pseudopalavras era bastante extensa, estabeleceu-se o mínimo de $25 \%$ de concordância entre os juízes para que a pseudopalavra pudesse ser considerada adequada para terapia. Com isso, obteve-se uma nova lista de pseudopalavras.

A fim de conferir mais confiabilidade, precisão estatística e validade, esta nova lista foi enviada a outros 5 Juízes Doutores (GJ2). Os critérios utilizados para seleção dos juízes do GJ2 foram os mesmos do GJ1, sendo todos doutores com prática na área de Fala e com assinatura do TCLE.

Esta etapa, envolvendo o GJ2, é importante porque esta validade aponta o quanto determinado item é importante para o objetivo ao qual foi planejado, ou seja, neste caso, a validade de conteúdo foi a medida determinante de quantas e quais pseudopalavras são adequadas para a terapia.

Os juízes do GJ2 foram instruídos a analisar as pseudopalavras (PSP) e classificá-las em "essencial”, "não essencial, mas útil”, ou "não essencial” à terapia fonológica. Todos os juízes receberam a seguinte explicação para realizar a classificação:

- Essencial: PSP ótimas, que com certeza seriam utilizadas na terapia;

- Não essencial, mas útil: PSP boas, que talvez utilize ou não na terapia;

- Não essencial: PSP razoável, que provavelmente não utilize na terapia.

Os dados obtidos pela avaliação do GJ2 foram tabulados e submetidos à análise através da Razão de Validade de Conteúdo (RVC). Para análise da concordância entre os juízes, consideraram-se os valores mínimos de RVC propostos por Lawshe ${ }^{(25)}$, com isto evitou-se o risco de a concordância ocorrer pelo acaso.

Para melhor compreensão dos procedimentos metodológicos adotados neste estudo, a Figura 1 apresenta um esquema da metodologia utilizada.

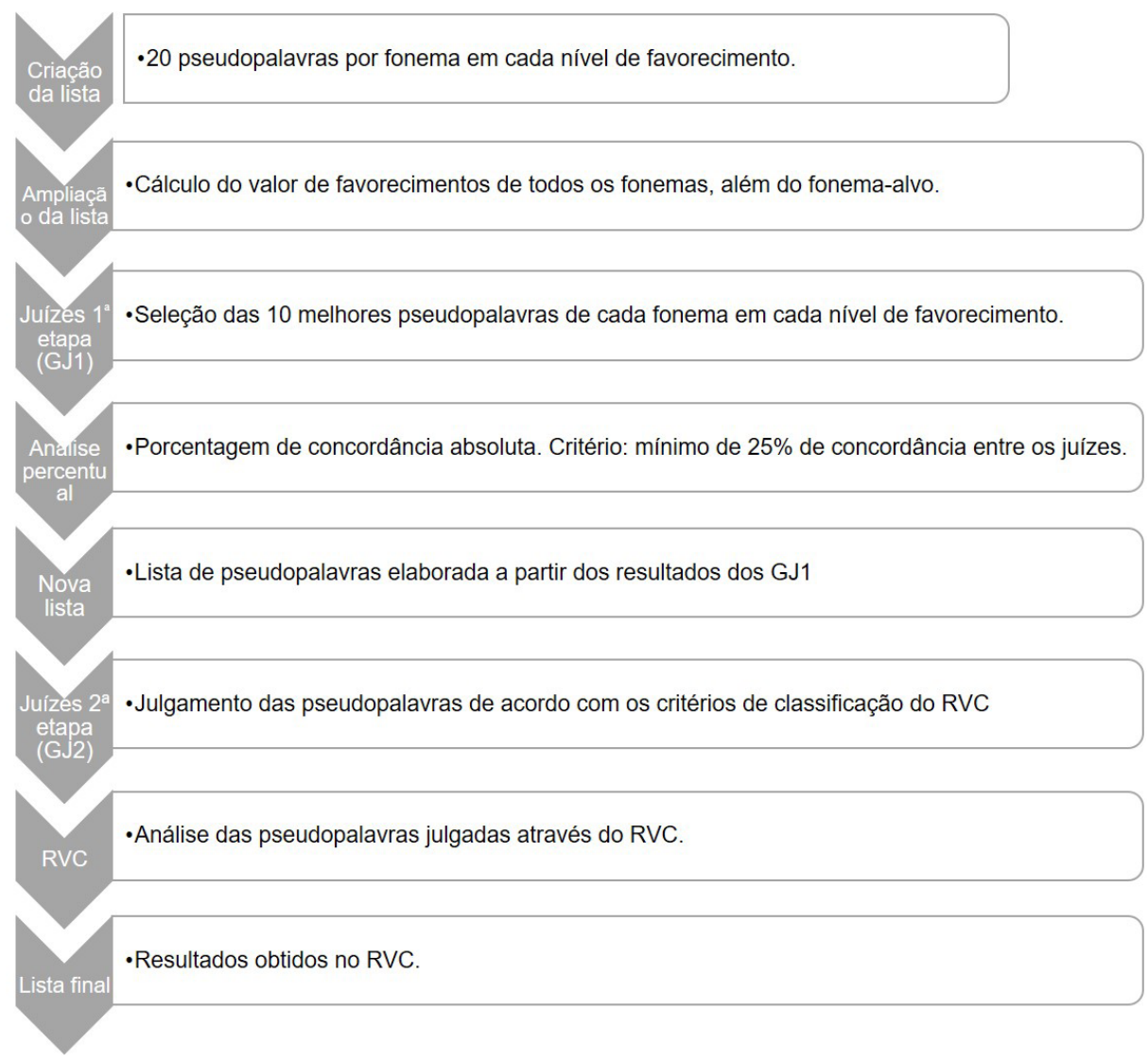

Legenda: RVC = Razão de Validade de Conteúdo

Figura 1. Esquema dos procedimentos utilizados na metodologia 


\section{RESULTADOS}

As pseudopalavras foram formuladas a partir de estruturas que respeitam as regras da língua portuguesa e que não são incomuns na fala das crianças. A tabela que segue apresenta o número de pseudopalavras criadas para cada fonema em cada nível de favorecimento.

Nota-se, na Tabela 1, que as plosivas são os fonemas para os quais mais foram criadas pseudopalavras, sendo seguidas pelos fonemas da classe das fricativas e nasais, fato justificado pela complexidade dos fonemas. Ainda, destaca-se o pequeno número de pseudopalavras criadas para o fonema /S/ no nível pouco favorecedor, e /1/ em onset complexo com fricativa no nível favorecedor.

O GJ1 analisou e selecionou as 10 melhores pseudopalavras de cada fonema em cada nível de favorecimento, porém a análise de um juiz precisou ser excluída devido à identificação da falta de critérios metodológicos na análise. Como justificativa para suas escolhas, os juízes apontaram principalmente os seguintes motivos: estrutura silábica simples - CV; palavras dissílabas; palavras com plosivas, e evitar líquidas; facilidade de produção; preferência por fonemas labiais e anteriores; sílaba tônica; diferentes contextos precedente e seguinte.

Após a análise do GJ1, de 4000 pseudopalavras, obteve-se uma lista de 1547 pseudopalavras, sendo 480 classificadas como pouco favorecedoras, 568 neutras e 499 favorecedoras. Conforme descrito na metodologia, esta nova lista foi analisada pelo GJ2, e cada pseudopalavra foi analisada separadamente através da RVC. Utilizaram-se as medidas do mínimo da RVC proposta por Lawshe ${ }^{(25)}$, a fim de evitar que a concordância no julgamento dos juízes ocorresse ao acaso.

Com a utilização deste critério proposto por Lawshe ${ }^{(25)}$, o número de pseudopalavras selecionadas pelos juízes reduziu consideravelmente. A tabela que segue apresenta as pseudopalavras selecionadas pelos juízes que obtiveram concordância pelo RVC, portanto, sem a possibilidade de ser selecionada ao acaso.

Na Tabela 2, observa-se que não houve uma preferência por fonema ou classe de sons na concordância dos juízes. Ainda, observa-se que, apesar de o ambiente linguístico ser controlado, os juízes selecionaram pseudopalavras mais "simples", ou seja, com estrutura silábica mais simples, CVCV. A maioria das pseudopalavras selecionadas pelos juízes eram dissílabas, com o fonema-alvo na posição tônica, e com os demais fonemas menos complexos que o alvo.

Das pseudopalavras analisadas e consideradas essenciais, Tabela 1, nenhuma pertencia ao ambiente pouco favorecedor, enquanto que no ambiente neutro houve apenas duas pseudopalavras (['ta.pi] e ['fle]). As demais pseudopalavras selecionadas eram de ambientes favorecedores.

Tabela 1. Número de pseudopalavras criadas para cada fonema e em cada nível de favorecimento

\begin{tabular}{|c|c|c|c|}
\hline Fonema-alvo & Pouco Favorecedoras & Neutras & Favorecedoras \\
\hline$/ \mathrm{p} /$ & 70 & 196 & 134 \\
\hline$/ \mathrm{b} /$ & 55 & 119 & 132 \\
\hline$/ \mathrm{t} /$ & 46 & 177 & 62 \\
\hline$/ d /$ & 64 & 143 & 55 \\
\hline$/ \mathbf{k} /$ & 31 & 159 & 100 \\
\hline$/ g /$ & 50 & 133 & 69 \\
\hline /f/ & 25 & 36 & 30 \\
\hline$/ v /$ & 30 & 76 & 40 \\
\hline /s/ & 29 & 64 & 21 \\
\hline $\mid z /$ & 33 & 76 & 32 \\
\hline /S/ & 15 & 62 & 27 \\
\hline /ZI & 27 & 58 & 32 \\
\hline /l/ & 20 & 83 & 33 \\
\hline II & 20 & 25 & 23 \\
\hline /R/ & 21 & 21 & 21 \\
\hline$/[/$ & 20 & 35 & 29 \\
\hline$/ \mathrm{m} /$ & 71 & 157 & 65 \\
\hline$/ \mathrm{n} /$ & 53 & 129 & 51 \\
\hline /ø/ & 30 & 34 & 46 \\
\hline /s/ coda & 20 & 25 & 48 \\
\hline /R/ coda & 43 & 58 & 42 \\
\hline $\mathrm{OC} / \mathrm{R} / \mathrm{p}$ & 20 & 23 & 31 \\
\hline OC/R/f & 20 & 20 & 21 \\
\hline$O C / 1 / p$ & 20 & 20 & 34 \\
\hline $\mathrm{OC} / \mathrm{I} / \mathrm{f}$ & 20 & 35 & 5 \\
\hline
\end{tabular}


Tabela 2. Pseudopalavras com validade de conteúdo sem interferência da concordância ao acaso

\begin{tabular}{|c|c|c|}
\hline Fonema-alvo & Pseudopalavra & RVC \\
\hline$/ p /$ & ['ta.pi] & 1 \\
\hline /R/ & [sa.'bi.ci] & 1 \\
\hline $\mathrm{OC} / \mathrm{l} / \mathrm{f}$ & {$\left[{ }^{\circ} \mathrm{f} \mid \varepsilon\right]$} & 1 \\
\hline$/ p /$ & ['pĩ] & 1 \\
\hline$/ d /$ & ['du.za] & 1 \\
\hline$/ g /$ & [ni.'go.ta] & 1 \\
\hline$/ g /$ & ['do.gu] & 1 \\
\hline$/ f /$ & ['fe.na] & 1 \\
\hline$/ f /$ & ['fe.ni] & 1 \\
\hline /R/ & ['Ri.ba] & 1 \\
\hline /R/ & ['Re.va] & 1 \\
\hline
\end{tabular}

Legenda: RVC = Razão de Validade de Conteúdo. Análise estatística utilizada RVC considerando os critérios de Lawshe ${ }^{(25)}$

\section{DISCUSSÃO}

Os ambientes favorecedores já foram alvo de diversos estudos $^{(3,5,6,6,17,18)}$, entretanto nenhum foi realizado buscando os ambientes para a pseudopalavras. O presente estudo buscou uma pesquisa que englobasse todos os ambientes favorecedores, e aplicou os resultados na criação de pseudopalavras, a fim de controlar o ambiente linguístico destas.

Os ambientes linguísticos foram importantes na criação das pseudopalavras, pois indicaram quais variáveis poderiam facilitar ou não a sua produção, além de indicar quais as possibilidades de ocorrência das variantes no PB.

A análise dos GJ1 evidenciou que as pseudopalavras constituídas por fonemas das classes de aquisição mais precoce, as consideradas de mais fácil produção, plosivas e fricativas, foram as mais selecionadas, ou seja, foram consideradas melhores para a terapia.

Ainda o pequeno número de pseudopalavras selecionadas para alguns fonemas pode ser justificado pelas restrições impostas pelos intervalos e pesos de favorecimento, obtidas no estudo dos ambientes favorecedores ${ }^{(24)}$. Exemplificando, de acordo com este estudo $^{(24)}$, o intervalo do nível pouco favorecedor para o fonema /S/ é de 0 a 5 e para a pseudopalavra atingir esta pontuação precisa necessariamente ser uma palavra monossílaba, com o fonema-alvo em onset inicial (consequentemente com a sílaba tônica e o contexto precedente vazio), e, no contexto seguinte, devem ocorrer as vogais [a], [e], [u], [o] ou [E]. Com isso, as possibilidades de criação de pseudopalavras ficaram muito limitadas.

A análise das pseudopalavras a partir do julgamento de juízes especialistas foi importante para este estudo, pois conferiu maior credibilidade aos resultados. Diversos estudos ${ }^{(20-23,26,27)}$ utilizaram a análise de juízes como método e comprovaram a eficiência do método.

A análise de concordância entre os juízes utilizando a medida da RVC foi baseada em estudos atuais ${ }^{(25)}$ que afirmam que esta medida é capaz de medir a concordância entre avaliadores sobre o quanto determinado item é essencial, e se é válido para aplicação na pesquisa e prática.
O pequeno número de pseudopalavras que apresentaram validade de conteúdo pode ser justificado pela quantidade de juízes, o mínimo necessário. Com isso, baseado nos critérios propostos por Lawshe ${ }^{(25)}$, o valor da RVC precisou ser muito elevado $(0,99)$, ou seja, todos os juízes deveriam concordar que a pseudopalavra é essencial.

No Brasil, as pseudopalavras são utilizadas tradicional e comumente em avaliações, sendo pouquíssimo utilizadas em terapia, especialmente as com enfoque fonológico. Entretanto, na literatura internacional seu uso em terapia é descrito há alguns anos ${ }^{(28,29)}$.

A incorporação de pseudopalavras à terapia fonológica funciona como um fator controlador de estímulos e representa uma diminuição significativa no risco de haver confusão e/ou associação com outras palavras-alvo, no caso com significado ${ }^{(30)}$.

Nos resultados, observou-se que, apesar de os ambientes linguístico serem controlados, os juízes consideraram algumas destas variáveis controladas como um critério de seleção para as pseudopalavras. A maioria dos juízes demonstraram preferência por alvos com estrutura simples (CV), sílaba tônica e palavras dissílabas. Estes dados concordam com dados encontrados na literatura ${ }^{(3,5,14)}$, os quais referem que os critérios citados (silaba tônica, estrutura CV) facilitam a aquisição dos fonemas.

\section{CONCLUSÕES}

A partir da criação de uma lista extensa, obteve-se um pequeno número de pseudopalavras que apresentam validade de conteúdo e podem ser utilizadas na terapia fonológica.

O pequeno número de juízes foi uma das limitações do estudo, pois, devido ao valor elevado de concordância necessária entre estes, o número de pseudopalavras ficou bastante reduzido. Apesar disso, estas pseudopalavras podem ser consideradas adequadas e validadas para a terapia, pois foram julgadas pelo número mínimo de juízes necessário.

Os resultados obtidos nas análises dos juízes são indicativos de que as pseudopalavras são um recurso pouco utilizado por fonoaudiólogos que ainda apresentam certa resistência na sua utilização.

A fim de confirmar a eficiência das pseudopalavras obtidas neste estudo, sugere-se a realização de um estudo utilizando-as na terapia fonológica.

\section{REFERÊNCIAS}

1. Mota HB, Bagetti T, Keske-Soares M, Pereira LP. A generalização baseada nas relações implicacionais em sujeitos submetidos à terapia fonológica. Pró-Fono R. Atual. Cient. 2005;17(1):99-110.

2. Mota HB, Keske-Soares M, Bagetti T, Ceron MI, Melo MGC Fa. Análise comparativa da eficiência de três diferentes modelos de terapia fonológica. Pró-Fono R. Atual. Cient. 2007;19(1):67-74. http://dx.doi.org/10.1590/ S0104-56872007000100008.

3. Keske-Soares M, Mota HB, Pagliarin KC, Ceron MI. Estudo sobre os ambientes favoráveis à produção da líquida não-lateral /r/ no tratamento do desvio fonológico. Rev Soc Bras Fonoaudiol. 2007;12(1):48-54. http:// dx.doi.org/10.1590/S1516-80342007000100010. 
4. Pagliarin KC, Keske-Soares M. Abordagens contrastivas na terapia dos desvios fonológicos: considerações teóricas. Rev CEFAC. 2007;9(3):330-8. http://dx.doi.org/10.1590/S1516-18462007000300006.

5. Keske-Soares M, Pagliarin KC, Ceron MI. Terapia Fonológica considerando as variáveis lingüísticas. Rev Soc Bras Fonoaudiol. 2009;14(2):261-6. http://dx.doi.org/10.1590/S1516-80342009000200019.

6. Gonçalves GF, Keske-Soares M, Checalin MA. Estudo do papel do contexto lingüístico no tratamento do desvio fonológico. Rev Soc Bras Fonoaudiol. 2010;15(1):96-102. http://dx.doi.org/10.1590/S1516-80342010000100016.

7. Pagliarin KC, Mota HB, Keske-Soares M. Generalização estrutural a partir do tratamento por diferentes modelos de oposições. Rev Soc Bras Fonoaudiol. 2011;16(3):356-61. http://dx.doi.org/10.1590/S1516-80342011000300019.

8. Pagliarin KC, Brancalioni AR, Keske-Soares M. Terapia fonológica a partir da estimulação de sons isolados e em conjunto. Rev Soc Bras Fonoaudiol. 2012;17(1):23-7. http://dx.doi.org/10.1590/S1516-80342012000100006.

9. Bonini JB, Bertagnolli APC, Freitas GP, Blanco-Dutra AP, Keske-Soares M. Eficácia de palavras favorecedoras com a fricativa/3/ na terapia fonológica. Rev. Distúrb Comun. 2014;26(2):395-404.

10. Melo RM, Backes FT, Mota HB. Percepções de pais/responsáveis de crianças com desvio fonológico acerca do desvio fonológico e da terapia fonoaudiológica. Rev CEFAC. 2015;17(6):1802-13. http://dx.doi. org/10.1590/1982-0216201517621314.

11. Gierut JA. Maximal opposition approach to phonological treatment. J Speech Hear Disord. 1989;54(1):9-19. http://dx.doi.org/10.1044/jshd.5401.09. PMid:2915530.

12. Gierut J. The conditions and course of clínically-induced phonological change. J Speech Hear Res. 1992;35(5):1049-63. http://dx.doi.org/10.1044/ jshr.3505.1049. PMid:1447917.

13. Santos FH, Bueno OF. Validation of the Brazilian Children's Test of Pseudoword Repetition in Portuguese speakers aged 4 to 10 years. Braz J Med Biol Res. 2003;36(11):1533-47. http://dx.doi.org/10.1590/S0100879X2003001100012. PMid:14576909.

14. Mezzomo CL, Baesso JS, Athayde ML, Dias RF, Giacchini V. O papel do contexto fonológico no desenvolvimento da fala: implicações para a terapia dos desvios fonológicos evolutivos. Let Hoje. 2008;43(3):15-21.

15. Athayde ML, Baesso JS, Dias RF, Giacchini V, Mezzomo CL. O papel das variáveis extralinguísticas idade e sexo no desenvolvimento da coda silábica. Rev Soc Bras Fonoaudiol. 2009;14(3):293-9. http://dx.doi. org/10.1590/S1516-80342009000300003.

16. Mezzomo CL, Mota HB, Dias RF, Giacchini V. Fatores relevantes para aquisição da coda lexical e morfológica no português brasileiro. Rev CEFAC. 2010;12(3):412-20. http://dx.doi.org/10.1590/S1516-18462010005000008.

17. Brancalioni AR, Bonini JBB, Gubiani MB, Keske-Soares M. Ambientes favorecedores para produção dos fonemas plosivo /k/ e /g/. Rev. Distúrb Comun. 2012;24(1):101-7.

18. Wiethan FM, Mota HB. Ambientes favoráveis para a produção de /z/, /J/e /Z/: análise e comparação das mudanças ocorridas no sistema fonológico.
Rev CEFAC. 2012;15(2):324-33. http://dx.doi.org/10.1590/S151618462012005000014.

19. Wertzner H, Papp A, Amaro L, Galea D. Relação entre processos fonológicos e classificação perceptiva de inteligibilidade de fala no transtorno fonológico. Rev Soc Bras Fonoaudiol. 2005;10(4):193-200.

20. Savoldi A, Ceron MI, Keske-Soares M. Quais são as melhores palavras para compor um instrumento de avaliação fonológica? Audiol Commun Res. 2013;18(3):194-202. http://dx.doi.org/10.1590/S2317-64312013000300009.

21. Marino VCC, Borges TSM, Jurado MRB, Canales MR, Lima-Gregio AM, Dutka JCR. Julgamento perceptivo-auditivo das oclusivas velares associadas à fissura labiopalatina por juízes com e sem experiência. Rev CEFAC. 2015;17(6):1916-28. http://dx.doi.org/10.1590/1982-021620151761814.

22. Donicht G, Pagliarin KC, Mota HB, Keske-Soares M. A inteligibilidade do desvio fonológico julgada por três grupos de julgadores. Pró-Fono R. Atual. Cient. 2009;21(3):213-8. http://dx.doi.org/10.1590/S010456872009000300006.

23. Donicht G, Pagliarin KC, Keske-Soares M, Mota HB. Julgamento perceptivo da gravidade do desvio fonológico por três grupos distintos. Rev CEFAC. 2010;12(1):21-6. http://dx.doi.org/10.1590/S1516-18462010000100004.

24. Bonini JB. Pseudopalavras favorecedoras para terapia fonológica [tese]. Santa Maria: Universidade Federal de Santa Maria; 2016.

25. Lawshe CH. A quantitative approach to contente validity. Person Psychol. 1975;28(4):563-75. http://dx.doi.org/10.1111/j.1744-6570.1975.tb01393.x.

26. Souza APR, Marques JM, Scott LC. Validação de itens para uma escala de avaliação da inteligibilidade de fala. Pró-Fono R. Atual. Cient. 2010;22(3):325-32. http://dx.doi.org/10.1590/S0104-56872010000300028.

27. Alexandre NMC, Coluci MZO. Validade de conteúdo nos processos de construção e adaptação de instrumentos de medidas. Cien Saude Colet. 2011;16(7):3061-8. http://dx.doi.org/10.1590/S1413-81232011000800006. PMid:21808894.

28. Munson B. Phonological pattern frequency and speech production in adults and children. J Speech Lang Hear Res. 2001;44(4):778-92. http://dx.doi. org/10.1044/1092-4388(2001/061). PMid:11521771.

29. Storkel HL. Learning new words: phonotactic probability in language development. J Speech Lang Hear Res. 2001;44(6):1321-37. http://dx.doi. org/10.1044/1092-4388(2001/103). PMid:11776368.

30. Gierut JA, Morrisette ML, Ziemer SM. Nonwords and generalization in children with phonological disorders. Am J Speech Lang Pathol. 2010;19(2):167-77. http://dx.doi.org/10.1044/1058-0360(2009/09-0020). PMid:20086043.

\section{Contribuição dos autores}

Ambas as autoras participaram da elaboração do artigo. JBB foi responsável pela coleta dos dados, tabulação dos dados, interpretação dos dados e elaboração do manuscrito; MKS foi responsável pela orientação da pesquisa, revisão e submissão do manuscrito. 